\title{
O GERENCIAMENTO DE CONFLITOS ENTRE A EQUIPE DE ENFERMAGEM*
}

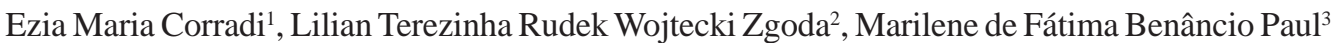

\begin{abstract}
RESUMO: Pesquisa exploratória descritiva realizada com 18 enfermeiros que atuam em saúde coletiva da rede pública do município de Colombo, região metropolitana de Curitiba. O objetivo foi analisar as características de gerenciamento entre enfermeiros. Os dados foram obtidos por meio de um questionário com questões abertas e fechadas e os resultados propiciaram caracterizar os enfermeiros quanto ao tempo de formação, tempo de atuação, fatores que influenciam e dificultam o relacionamento da equipe de trabalho, conseqüências de conflitos; qualidades, ações e dificuldades do enfermeiro para conseguir o comprometimento do grupo. Conclui-se que o diálogo é ferramenta útil para gerenciar conflitos que devem ser vistos como oportunidade de crescimento e que os enfermeiros devem utilizar e conciliar habilidades técnicas, humanas e conceituais, como mais uma maneira profissional de conduzir seu trabalho
\end{abstract}

PALAVRAS-CHAVE: Equipe de enfermagem; Relações interprofissionais; Serviços de saúde.

\section{CONFLICT MANAGEMENT AMONG THE NURSING TEAM}

\begin{abstract}
Descriptive exploratory research study carried out with 18 nurses from public collective health units in the municipality of Colombo, metropolitan region of Curitiba, Parana State/Brazil. It aimed to analyze management characteristics among nurses. Data collection was performed by means of a questionnaire with open and closed questions and results enabled to feature nurses regarding educational level, work time-length, factors that influence and make relationship among nursing team difficult, consequences of conflicts; qualities, action and difficulties of nurses to reach team commitment. It is concluded that dialogue is a useful tool to manage conflicts which must be seen as growth opportunities and nurses must also use and share technical, human and conceptual skills as a professional way to perform their work.
\end{abstract}

KEYWORDS: Nursing team, Interprofessional Relationships, Health Services.

\section{ADMINISTRACIÓN DE CONFLICTOS ENTRE EL EQUIPO DE ENFERMERÍA}

RESUMEN: El estudio analiza las características de la administración de conflictos con enfermeros de la ciudad de Colombo, Curitiba, en estado de Paraná. Los datos fueron recogidos por medio de cuestiones abiertas y cerradas y los resultados posibilitaron caracterizar los enfermeros según el tiempo de formación, tiempo de actuación, factores que influencian y dificultan la relación del equipp de trabajo, consecuencias de conflictos; cualidades, acciones e dificultades del enfermero para lograr el comprometimiento del grupo. Se concluye que el diálogo es herramienta útil para administrar conflictos que deben ser vistos como oportunidad de crecimiento y que los enfermeros deben utilizar y conciliar habilidades técnicas, humanas y conceptuales, como una forma profesional de conducir su trabajo

DESCRIPTORES: Grupo de Enfermería; Relaciones Interprofesionales; Servicios de Salud

*Trabalho de conclusão de Curso de Especialização em Gerenciamento dos Serviços de Enfermagem da Pontifícia Universidade Católica do Paraná-PUC-PR. 2006.

${ }^{1}$ Enfermeira. Mestre em Educação. Professor Adjunto do Curso de Graduação em Enfermagem da PUC-PR.

${ }^{2}$ Enfermeira. Especialista em Gerenciamento de Serviços de Enfermagem. Coordenadora da Vigilância Sanitária da Prefeitura Municipal de Colombo.

${ }^{3}$ Enfermeira. Especialista em Gerenciamento de Serviços de Enfermagem.

Autor correspondente:

Ezia Maria Corradi

Rua Prof. Benedito Conceição, 448 - 82810-08 - Curitiba-PR

Recebido: 11/11/07

E-mail: ezia.corradi@pucpr.br

Aprovado: 22/04/08

Cogitare Enferm 2008 Jan/Mar; 13(2):184-93 


\section{INTRODUÇÃO}

As organizações com foco na gestão de pessoas consideram-nas realmente como capital humano e como diferencial para o alcance de resultados. Também, essas organizações dão atenção especial para o clima interno de trabalho, permeado pela qualidade do relacionamento entre as pessoas.

O relacionamento no trabalho é um processo complexo, pois cada pessoa traz consigo ligações por laços profissionais, afetivos, amizades e afinidades, sendo condicionadas por uma série de atitudes recíprocas. Conseqüentemente, essas características possibilitam ao trabalhador conviver com maior ou menor habilidade com seus pares nos locais de trabalho ${ }^{(1)}$.

Na prática profissional percebem-se malentendidos, desconfianças, sentimentos de coerção, egoísmo, desrespeito e irritação mostrando diferenças individuais manifestas no ambiente de trabalho, em decorrência de mau relacionamento. O relacionamento mais ou menos harmonioso no trabalho exige da gerência competências para resolver as diferenças, utilizando ferramentas úteis, visando o fortalecimento de fatores facilitadores levando a construção coletiva de equipe, trabalho este relevante na equipe de saúde e em especial na equipe de enfermagem.

A necessidade do desenvolvimento contínuo das competências e habilidades para o trabalho em equipe, convivendo lado a lado com as diversidades culturais, sociais, e econômicas das pessoas envolvidas na organização é um dos desafios dos gestores enfermeiros. Este é o foco desta pesquisa e justificase porque o trabalho em equipe na área da saúde requer trabalho cooperativo, percepção criativa, visão positiva de conflitos, entre outras habilidades dos enfermeiros para gerir inter-relações de forma competente e sincronizada em busca de objetivos comuns.

Diante do exposto o objetivo dessa pesquisa foi analisar as características de gerenciamento entre enfermeiros que atuam em saúde coletiva. Especificamente, buscou-se descrever causas geradoras de conflitos no contexto da enfermagem e propor alternativas para melhoria no relacionamento do ambiente de trabalho.

\section{REFERENCIAL TEÓRICO}

Na história da humanidade a sociedade passa por diversas transformações sociais, políticas, industriais e tecnológicas. Dentre essas transformações os avanços, em especial, da ciência e tecnologia tornaram os ambientes de trabalho mais competitivos e com maior possibilidade de conflitos. Logo, a interdependência de pessoas nas situações relacionadas ao âmbito de trabalho têm merecido estudos para compreender como se dão e como minimizar possíveis problemas dela decorrente.

Em saúde, cujos avanços são extraordinários, o trabalho é uma modalidade coletiva, reunindo diversas categorias profissionais, em diferentes níveis de formação, em turnos ininterruptos a serviço da assistência às pessoas com diversos níveis de agravos à vida ${ }^{(2)}$.

A formação do profissional de enfermagem e sua articulação com o mercado de trabalho tem como marco histórico o trabalho realizado, na década de 1950, pela Associação Brasileira de Enfermagem (ABEn), que deu origem ao relatório final de levantamento de recursos e as necessidades no cotidiano dos serviços de saúde ${ }^{(3)}$.

Atualmente, a necessidade de mudanças constantes tem impulsionado novas idéias, gerando novos conhecimentos aos enfermeiros líderes à busca de novos modelos de gerenciamento no âmbito da saúde, devendo este ser um desafio para aqueles que buscam destaque no mercado de trabalho. Portanto, a dupla dimensão do processo de trabalho do enfermeiro, que contempla ações assistenciais e de gerenciamento, deve ser entendida como fonte inesgotável de aquisição de habilidades e competências. No entanto, o modelo funcional das organizações, ainda muito utilizada nas organizações, que se caracteriza pelo trabalho centrado nas tarefas e sem solução para a escassez de recursos humanos $^{(2)}$, não responde satisfatoriamente às necessidades de qualidade de assistência e das interrelações de equipes de enfermagem.

Por outro lado, em qualquer organização que exista interação entre indivíduos há situações conflituosas, tornando de grande valia conhecimentos do gestor para elaborar a melhor maneira de resolvêlas e/ou negociá-las. O conflito ou situação conflituosa é entendido como divergências de idéias e percepções dos indivíduos envolvidos. Gera instabilidade entre relações tornando-se negativo ou não, dependendo de como as pessoas lidam com ele, ou seja, se as emoções determinarem como conduzir o conflito há grande probabilidade de que tome o caráter negativo e produza efeitos desastrosos nas relações ${ }^{(4)}$.

Para que se possa administrar satisfatoriamente o conflito, é necessário entender o seu processo, que 
ocorre em cinco estágios: o primeiro é o conflito latente, por condições que favoreçam o surgimento de um conflito, ou seja, situações que ainda não ocorreram, mas que representam condições para o seu surgimento. O segundo refere-se ao conflito percebido, algo que os envolvidos percebem que está ocorrendo. O terceiro é o conflito sentido, quando o mesmo se torna emoção. O quarto é o conflito manifesto, estágio em que se manifestam ações e busca de soluções para sua resolução. $\mathrm{O}$ último refere à conseqüência do conflito, ou seja, a avaliação de como o mesmo foi resolvido. Caso seja resolvido de forma racional e coerente, em que todos foram beneficiados ou tiveram ambas as partes seus propósitos adquiridos, pode-se afirmar que o conflito foi bem administrado. Entretanto, se o contrário ocorrer, as questões ficam oprimidas, podendo a situação conflituosa reincidir de forma mais intensa, acarretando maior desgaste emocional e o conflito resolvido de maneira insatisfatória ${ }^{(5)}$.

O enfermeiro como gestor deverá gerenciar os conflitos, para tanto deverá conhecer e aplicar quatro estratégias: acomodação, dominação, compromisso e solução interativa dos problemas, utilizando-as conforme cada situação ${ }^{(6)}$. Na acomodação ocorre o encobrimento dos problemas, buscando resgatar a harmonia, entretanto o problema fica implícito, pois não foi resolvido e pode ressurgir a qualquer momento, acompanhado pela carga emocional que nele foi depositado. A dominação é a disputa pelo poder, prevalece a decisão de quem tem mais representatividade, esse processo não dá margens a negociações e sempre um perde para que o outro possa vencer. O compromisso se apresenta quando cada envolvido tem que ceder um pouco, renunciar questões de menor relevância, preservando e negociando a essência. O que ficou para trás será negociado em outra oportunidade. Finalmente, a solução interativa dos problemas visa buscar soluções alternativas que satisfaçam as partes.

A negociação para ser bem sucedida depende do conhecimento de suas três fases: a primeira consiste na Preparação, pois para negociar a pessoa deverá estar bem interada sobre o assunto/problema a ser tratado, verificar até quando e quanto pode ceder e quais as estratégias que serão utilizadas para conquistar seus interesses. A Mesa de Negociações é o momento de colocar a estratégia em prática, para isto deve-se criar um clima propício, apresentar a proposta e fazer concessões, para evitar impasse. A última fase é o Controle e Avaliação. Ao final da negociação deve-se estar atento se o que foi acordado será cumprido, para isto registra-se formalmente e ambas as partes assinam o acordo.

Saber negociar depende de cada indivíduo, pois há fatores que podem influenciar, como cultura, crenças, valores, costumes, grau de conhecimento do problema, sentimentos, entre outros, contudo deve ser conduzido de forma amigável, independente do problema/conflito o resultado da negociação deve ser satisfatório para ambas as partes. Baseado nestes pressupostos, faz-se necessário que o profissional enfermeiro adquira conhecimentos para gerenciar essas situações conflituosas e desenvolva habilidades em realizar negociações. Mesmo sem esses conhecimentos sobre conflitos e negociações já se desenvolve no cotidiano maneiras de negociações para que os objetivos sejam alcançados, porém quando se busca o conhecimento, estamos descobrindo maneiras e métodos de como identificar, analisar e descobrir a melhor forma de negociar os problemas, com menor desgaste emocional e maior assertividade, fazendo com que ambas as partes sejam beneficiadas, não esquecendo de utilizar como ferramenta as questões éticas.

\section{METODOLOGIA}

Esta pesquisa descritiva exploratória foi realizada com todos os 18 enfermeiros com cargos de chefia na área de saúde coletiva, locados em Unidades Básicas de Saúde, Programas Saúde da Família e Unidades de Saúde 24 horas, Secretaria Municipal de Saúde, Vigilância Sanitária e Vigilância Epidemiológica, do município de Colombo, região metropolitana de Curitiba.

$\mathrm{Na}$ a coleta de dados, realizada entre agosto e setembro de 2006, foi utilizado um instrumento autoaplicável, com perguntas abertas e fechadas com os objetivos de caracterizar os enfermeiros quanto ao tempo de formação, cursos na área de gerenciamento, tempo de atuação, fatores que influenciam e dificultam o relacionamento da equipe de trabalho, conseqüências de conflitos entre os membros da equipe; qualidades, ações e dificuldades do enfermeiro para conseguir o comprometimento do grupo. As respostas foram levadas em conta para a estruturação das categorias de análise e foram tabuladas, por aproximação de semelhanças.

Foram prestados esclarecimentos prévios aos entrevistados que assinaram o Termo de Consentimento Livre e Esclarecido. O projeto foi aprovado pelo Comitê de Ética em Pesquisa da PUCPR sob o n ${ }^{\circ}$. 1277, de 16 de agosto de 2006. 


\section{APRESENTAÇÃO E ANÁLISE DOS DADOS}

\section{Caracterização da população de estudo}
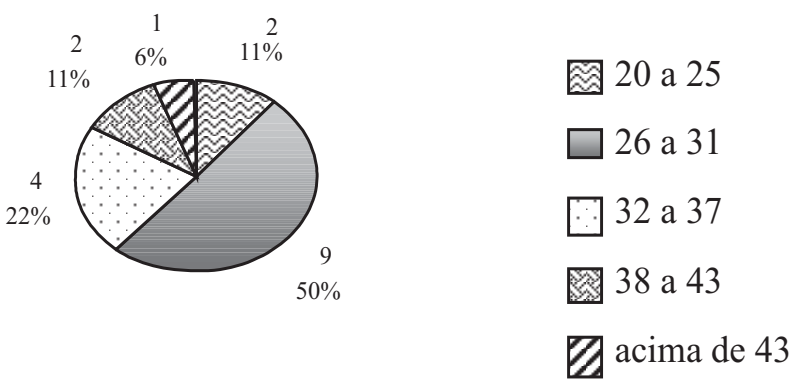

Gráfico 1 - Caracterização dos enfermeiros por faixa etária. Colombo/PR, 2006

Dos 18 enfermeiros do estudo, 50\% (9) apresentam idades entre 26 a 31 anos, 22\% (4) entre 32 a 37 anos, $11 \%$ (2) entre 20 a 25 anos e 38 a 43 anos respectivamente e (6\%) (1) com idade acima de 43 anos.

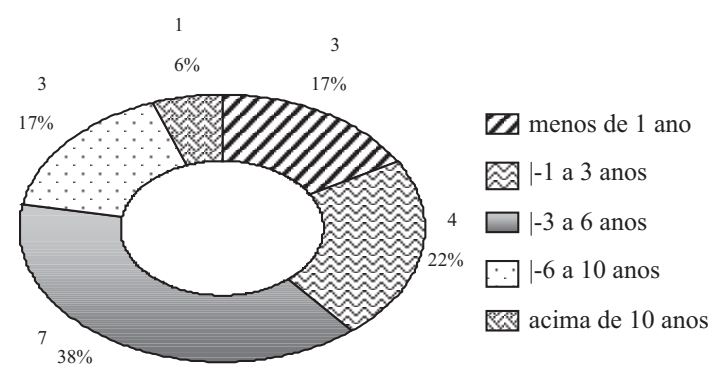

Gráfico 2 - Tempo de conclusão do curso de graduação dos enfermeiros. Colombo/PR, 2006

Com relação ao tempo de formação no curso de Enfermagem pelos enfermeiros (38\%) (7) possuem de 3 a 6 anos, (22\%) (4) de 1 a 3 anos, com 17\% (3) de 6 a 10 anos, 17\% (3) com formação inferior a um ano, e, 6\% (1) com mais de 10 anos de conclusão do curso superior.

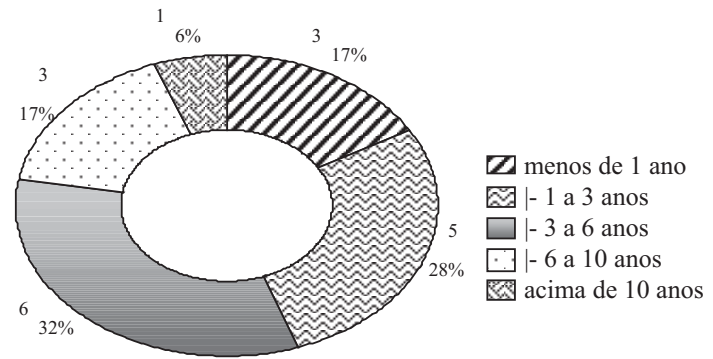

Gráfico 3 - Tempo de atuação profissional dos enfermeiros. Colombo/PR, 2006
Com relação à caracterização dos enfermeiros por tempo de atuação na profissão, verifica-se que $32 \%$ (6) atuam de 3 a 6 anos, 28\% (5) de 1 a 3 anos, 17\% (3) há menos de um ano e de 6 a 10 anos respectivamente e 6\% (1) acima de 10 anos. Destes 89\% (16) possuem cargo de coordenação na instituição, das quais 50\% (8) há menos de 1 ano, 25\% (4) de 1 a 3 anos, 19\% (3) de 3 a 6 anos e $6 \%$ (1) acima de 10 anos.

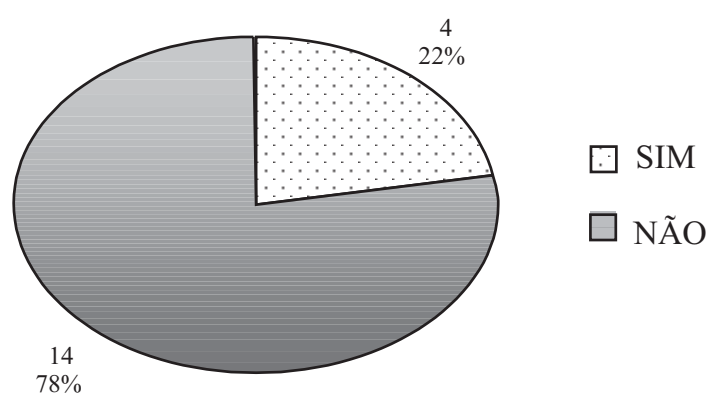

Gráfico 4 - Participação dos enfermeiros em cursos de gerenciamento em saúde. Colombo/PR, 2006

Dos 18 enfermeiros (22\%) (4) realizaram cursos na área de gerenciamento e (78\%) (14) não realizaram nenhum curso nesta especialidade. Dos enfermeiros que realizaram algum curso nesta modalidade, um fez o curso de pós-graduação em Administração com ênfase em saúde, um cursou residência multiprofissional em Programa Saúde da Família, um em Administração em Saúde Pública (MBA, gestão de pessoas) e um em Gerenciamento dos serviços de Enfermagem e curso de Chefia versus liderança.

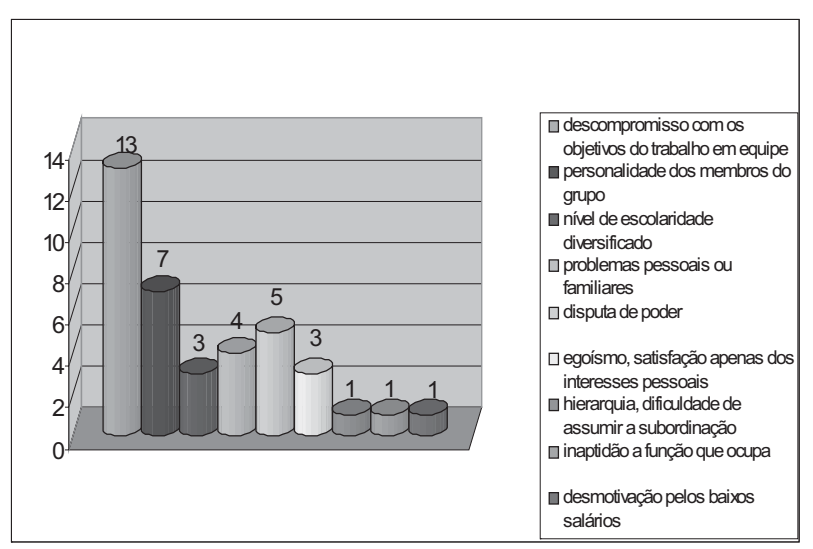

Gráfico 5 - Opiniões dos enfermeiros sobre os fatores que interferem negativamente no relacionamento da equipe de trabalho. Colombo/PR, 2006

Sobre os fatores que influenciam as relações no trabalho, perguntou-se aos enfermeiros, a partir de suas experiências profissionais, quais seriam aqueles 
que mereceriam destaque no sentido de dificultar de alguma maneira as inter-relações. As respostas foram agrupadas por aproximação de significado e 13 enfermeiros (34\%) opinaram sobre o descompromisso com os objetivos do trabalho; $18,5 \%$ expuseram que no grupo de trabalho há pessoas com diferentes modos de ver, pensar e fazer as atividades, bem como de se relacionar com seus pares. Esse agrupamento foi denominado pelos entrevistados como "personalidade dos membros do grupo". Houve ainda relato de disputa de poder entre os integrantes (13\%), problemas pessoais e com familiares interferindo no desempenho profissional (10,5\%), "nível de escolaridade diversificado" compreendeu os diferentes níveis de instrução formal entre os profissionais de saúde (8\%) e busca da satisfação dos interesses pessoais, compreendida entre os entrevistados como "egoísmo" representou 8\%.

Outros fatores relatados pelos participantes foram a desmotivação pelos baixos salários, relações conflituosas em diferentes níveis hierárquicos, problemas no desempenho de funções pela falta de conhecimentos e habilidades, agrupado como "inaptidão à função que ocupa".

Em relação à falta de motivação, relatada pelos enfermeiros, destaca-se que é entendida como a impossibilidade de atender as necessidades insatisfeitas, constituindo em uma força que pode ou não estimular a agir. Neste sentido, apontaram como desencadeadores de desmotivação os baixos salários, questões hierárquicas, problemas com as condições de trabalho e outros.

As respostas dos enfermeiros mostram quão desafiante é o trabalho entre os profissionais. Podese inferir, então, que no grupo pesquisado falta o sentimento de equipe, pois uma equipe caracteriza-se pelo conjunto de pessoas alinhadas com objetivos e comprometidas com os resultados do trabalho, diferenciando basicamente de um grupo onde apesar de existir uma reunião de pessoas, não se encontra presente um alinhamento a propósitos comuns ${ }^{(1: 99)}$.

Certamente há os fatores externos às unidades que interferem nas relações, possivelmente falta de treinamento e condições favoráveis ao desempenho de atividades laborativas que possam auxiliar na satisfação no trabalho e torná-lo ação produtiva e como interação social.

Os apontamentos dos enfermeiros remetem ao fato de que as relações interpessoais nos ambientes de trabalho deveriam ocorrer de forma interativa, com interesses profissionais, afetivos, amizades comuns.
As afinidades são condicionadas por atitudes muitas vezes recíprocas e assim, as habilidades no processo interpessoal transparecem por habilidades de convivência entre os profissionais, permitindo que $o$ relacionamento ocorra de forma equilibrada, construtiva e prazerosa.

Em relacionamentos cada pessoa traz consigo diferentes percepções, valores e conhecimentos, o que determina que uma mesma questão seja olhada de diferentes formas. Assim sendo, as diferenças individuais se manifestam no trabalho sob a forma de comportamentos e atitudes, como: diferentes interesses e opiniões, disputas pelo poder, egoísmo, obstinação, entre outros, conduzindo muitas vezes à perda de foco nos objetivos principais ${ }^{(1: 96)}$.

Na tentativa de encontrar o equilíbrio e relações saudáveis no trabalho, a ênfase deve estar centrada em boas relações humanas; em elevada consideração dos padrões éticos; na comunicação adequada e no espírito de equipe; situação que somente se viabilizará por meio de respeito mútuo, transparência nas atitudes, reconhecimento da individualidade, disposição em oferecer e receber ajuda, evitando-se os préjulgamentos e confrontos imaturos desgastantes.

Nessa pesquisa, uma possibilidade para minimizar os enfrentamentos dos enfermeiros seria propiciar maior diálogo entre e com grupo de diferentes níveis hierárquicos, por meio de reuniões formais e informais que possibilitassem maior e melhor comunicação, possibilitando a formação de vínculos de confiança, tolerância, bom humor, troca de informações, ajuda, apoio e cordialidade. Afinal, fatores bloqueadores do relacionamento são desconfiança, medo, boatos, intrigas, ênfase nos erros e pontos fracos ${ }^{(1: 97)}$.
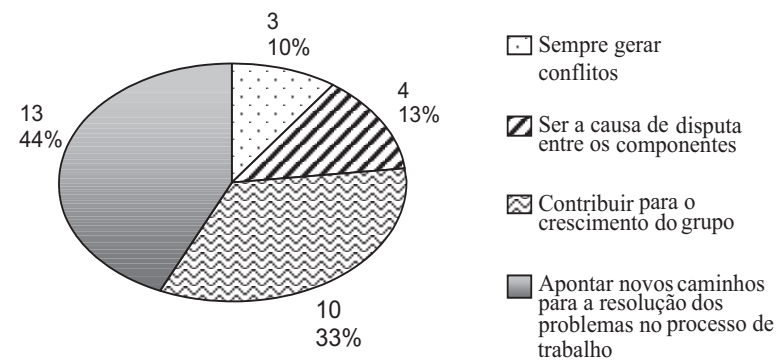

Gráfico 6 - Opinião dos enfermeiros sobre a convivência em grupo de trabalho. Colombo/PR, 2006

Com relação a convivência de uma equipe de trabalho, 44\% (13) enfermeiros acreditam que pessoas diferentes apontam novos caminhos para a resolução 
dos problemas no processo de trabalho, (33\%) (1) acredita que este fator contribui para o crescimento do grupo, (13\%) (4) acreditam ser a causa de disputa entre os componentes e (10\%) (3) afirmam que as diferenças geram sempre conflitos.

A maioria dos enfermeiros entende a situação de conflito de maneira positiva a qual apresenta efeitos benéficos, oportuniza incrementar o entendimento das diferentes perspectivas de análise dos problemas e que esses contribuem para o crescimento da equipe. Por outro lado, (7) percebem o conflito como experiência negativa, podendo assumir um estilo de gerenciamento pela abordagem de evasão, ou seja, evitar o conflito a qualquer custo ou, ainda, assumir posição neutra ou de distanciamento (não ver, não ouvir, não falar de discordâncias), fugindo à responsabilidade social até o caso extremo de alienação. Outra possibilidade é assumir a abordagem da harmonização quando prefere-se aceitação pessoal, doçura e paz à validade das soluções; discordâncias evitadas podem causar ressentimentos, conseguindose pouca cordialidade e concordância superficial à custa de convicções pessoais e criatividade ${ }^{(6)}$.

Ainda, se os conflitos são a causa de disputa entre os componentes, pode-se utilizar a forma de gerenciá-los pensando em supressão, controlando situações conflituosas utilizando-se da força, situação polarizada de ganha-perde, autoridade-obediência, de antagonismo e de competição, em que ganhar (impor sua solução ou decisão) é mais importante que procurar uma situação válida, adequada.

Em síntese, pode-se optar por dois tipos de abordagem, a acomodação quando o conflito é superado por negociação; busca de solução intermediária, em que ninguém perde tudo, mas também ninguém ganha tudo, chegando-se ao melhor acordo que se possa obter, embora não seja o mais adequado. A confrontação se apresenta como uma abordagem difícil de resolução de problemas em que idéias e sentimentos são discutidos abertamente, trabalhando-se nas e com as discordâncias para alcançar a uma solução válida para ambos. Não há vencidos e vencedores, os oponentes tornam-se colaboradores.

Para os entrevistados as qualidades que o enfermeiro deve possuir para conseguir o comprometimento dos membros do grupo, para um objetivo em comum são apresentadas no Quadro 1.

Quadro 1 - Opinião dos enfermeiros sobre atitudes e comportamentos que possibilitam maior comprometimento de equipe de trabalho. Colombo/PR, 2006

Relacionados ao trabalho com e entre a equipe

Administração

Competência

Conhecimento técnico e científico

Delegar funções

Diálogo

Ética

Liderança

Realizar assistência com a equipe

Realizar planejamento

Reconhecimento/valorização da importância do trabalho dos outros

Responsabilidade e interesse em resolver os problemas

Ser justo com todos

Supervisão

Tomada de decisões

Visão holística
Relacionados às atitudes e comportamentos pessoais e com a equipe

Autocontrole

Bom senso

Calma

Comprometimento com a equipe de trabalho

Confiança

Dinamismo

Discernimento

Empatia

Honestidade

Imparcialidade

Pontualidade

Saber ouvir

Sinceridade

Tranquiilidade 
Solicitou-se que os enfermeiros respondessem como se portam ou deveriam de portar para facilitar o comprometimento da equipe de enfermagem aos objetivos do serviço. Portar-se foi definido com características inerentes à própria pessoa, traduzindose em qualidades pessoais que norteiam suas ações, sendo de imensurável relevância para o exercício de suas atividades profissionais ${ }^{(1)}$.

As respostas foram tabuladas por aproximação de significado e categorizadas entre aquelas relacionadas ao trabalho dos enfermeiros como líder de equipe e aquelas próprias nas suas interrelações. Os enfermeiros responderam sob a ótica de suas experiências profissionais e sem que definissem os significados que atribuíam a cada um dos comportamentos, atitudes ou posturas descritas.

As posturas listadas nas duas colunas têm semelhança com as características de um líder. Para ser líder um indivíduo deve possuir alguns atributos, dentre eles destacam-se ${ }^{(1)}$ : visão holística do ambiente de trabalho; credibilidade; integridade, entendida como ser justo, sincero, honesto consigo mesmo e com os outros, apresentando transparência e ética; responsabilidade; determinação, em especial, coragem e reações emocionais coerentes para direcionar pessoas e grupos; entusiasmo; dedicação; humildade que prioriza o valor que lhe é atribuído por suas realizações e competência; gentileza e respeito e honestidade. Agir com calma e tranqüilidade; reconhecimento como valorizar as pessoas, encorajando-as, delegando responsabilidades e reconhecendo seu esforço, que se reflete na motivação, comprometimento e lealdade; capacidade intelectual e conhecimentos, pois são necessários para nortear ações eficazes e alcançar resultados. Inclui a capacidade de planejar, tomar decisões, supervisionar, administrar, realizar assistência. Flexibilidade, reconhecendo que saber ouvir é tão importante quanto falar; e, senso de humor/bom senso - característica que predispõe a criação de ambientes de trabalho mais produtivos e saudáveis.

Convém destacar que alguns atributos têm sua origem na personalidade (exemplo, integridade); outros, nas características pessoais (flexibilidade) e outros nas capacidades individuais (compreensão dos conceitos) ${ }^{(1)}$.

Quadro 2 - Ações dos enfermeiros diante de conflitos. Colombo/PR, 2006

\begin{tabular}{|ll|}
\hline Relacionados ao trabalho com e entre a equipe & Relacionados às atitudes e comportamentos pessoais e com as equipes \\
\hline Promover motivação & Ser imparcial \\
Determinar objetivos & Saber se colocar no lugar do outro \\
Promover comunicação & Ter postura ética \\
Promover integração & Respeitar as divergências \\
Expondo os pontos conflitantes & Usar bom senso \\
Trabalhar em equipe & Utilizar o conhecimento \\
Utilizar ferramentas administrativas & Valorizar a importância de cada membro do grupo \\
\hline
\end{tabular}

Foi solicitado aos 18 enfermeiros da pesquisa que respondessem quais as suas ações mediante os conflitos. As respostas obtidas, por aproximação de significado, apontam para o enfrentamento do conflito no enfoque gerencial contemporâneo, entendido como oportunidade para melhorar as interrelações e o trabalho em saúde.

Trata-se do oposto à visão clássica de suprimir os conflitos, já que estes são vistos de forma negativa. Nos paradigmas que embasam a teoria das relações humanas, tenta-se curar o conflito, pois ele é visto como uma doença. O enfoque gerencial contemporâneo, a partir da década de 80 com a globalização e a abertura de mercado, entende-se as necessidades, dificuldades, os pontos de vistas e as propostas do outro, buscando soluções criativas, conciliatórias e de qualidade para os problemas e interesses de todos os envolvidos, para tanto, o enfermeiro como um líder, deve utilizar ferramentas administrativas, através do seu conhecimento teórico e prático, para interferir na gestão de pessoas ${ }^{(6)}$.

Destaca-se que sentimentos, valores e crenças direcionam o enfermeiro para agir diante das situações de conflito; seu comprometimento com clientes, funcionários e com os próprios ideais. Auxiliam no direcionamento de planejar, tomar decisões, supervisionar, administrar, realizar assistência.

Refletir e agir em problemas e encontrar novas soluções contribuem para o crescimento do grupo, 
através do processo de comunicação, oportunizando o surgimento de novas idéias, construindo assim conhecimentos por meio das divergências de opiniões, transformando positivamente as situações conflitivas em resolução dos problemas da equipe de trabalho.

Quadro 3 - Problemas encontrados em equipe de trabalho, segundo as entrevistas realizadas com enfermeiros. Colombo/ PR, 2006

\begin{tabular}{|ll|}
\hline Relacionados ao trabalho do enfermeiro com o a equipe & $\begin{array}{l}\text { Relacionados às atitudes e comportamentos pessoais e com } \\
\text { as equipes }\end{array}$ \\
\hline Ausência de um líder & Falta de afinidade entre os profissionais \\
Ausência de diálogo & $\begin{array}{l}\text { Desmotivação por baixos salários } \\
\text { Nesrespeito }\end{array}$ \\
Fão saber lidar com a diversidade ética & Disputa de poder \\
O enfermeiro fomentando a geração de conflito & Resistência á mudanças \\
Jornada de trabalho excessiva & Falsidade \\
Deficiência de conhecimento técnico e científico & Falta de coleguismo/companheirismo \\
Descompromisso dos líderes com os liderados & Fofocas \\
Desrespeito hierárquico & Dificuldade de relacionamento interpessoal \\
& Falta de comprometimento profissional \\
& Incompatibilidade de objetivos \\
\hline
\end{tabular}

As respostas dos participantes desta pesquisa sobre as principais dificuldades nos relacionamentos de equipes no trabalho foram categorizadas em dois subgrupos, um corresponde a primeira coluna e trata de dificuldades a serem superadas pelos enfermeiros e no segundo aquelas relacionadas entre o grupo, sob a liderança do enfermeiro.

As dificuldades apontam, no geral, para questões de incompatibilidades pessoais e com o ambiente de trabalho. Parte dessas dificuldades talvez seja comprometer-se significando envolver-se com os projetos, objetivos ou metas daquilo que se deseja atingir, assumindo a responsabilidade integralmente pelos resultados das ações praticadas ${ }^{(1)}$, não existe comprometimento se as pessoas não participarem da elaboração dos projetos bem como do controle dos resultados. Tais dificuldades podem ser geradoras de estresse. O estresse profissional, conseqüente da insatisfação profissional, pode provocar fatores, como: irritabilidade, depressão ou excitação, perda de interesse, estagnação profissional e desmotivação, podendo resultar em baixa qualidade nos serviços prestados pelo profissional ${ }^{(8)}$.

Por outro lado, o comprometimento encontrase relacionado à inclusão das pessoas nos projetos de trabalho, dando-lhes autonomia e responsabilidade para tomar decisões próprias e conscientes no seu campo de atuação, levando em consideração as normas éticas e morais do ambiente em que trabalham. Pessoas não comprometidas não criam elos com o trabalho que executam nem demonstram preocupação com os resultados da organização, esse é o grande desafio do profissional enfermeiro.

Como líder deve promover integração, planejar, traçar metas juntamente com os membros do grupo, envolvê-los em busca dos objetivos comuns, gerenciar os conflitos de maneira positiva, ou seja, visualizá-los como meio de crescimento grupal aproveitando as idéias, promover a participação de todos os envolvidos, desta forma o enfermeiro poderá exercer liderança. Além de promover comprometimento estará promovendo um ambiente de trabalho agradável, com todos se sentindo motivados, valorizados, oportunizando melhoria no relacionamento interpessoal e promovendo o processo de comunicação.

O enfermeiro também poderá melhorar ou até mesmo corrigir a deficiência de conhecimento técnico científico pessoal e da equipe, por meio da implantação de educação em serviço ou educação continuada, trazendo os membros para os objetivos da organização pela construção do conhecimento.

Nos problemas como falta de ética, fofocas, desrespeito, falsidade, falta de companheirismo e coleguismo, impontualidade, resistência à mudanças o 
enfermeiro poderá trabalhar individualmente com os membros que apresentam estas características e tentar resgatar valores e propor metas.

Outras situações que dificultam o trabalho do enfermeiro e sua equipe num serviço público são influências externas aos seus locais de trabalho, como as políticas públicas, a desmotivação pelos baixos salários, a jornada de trabalho excessiva, que o enfermeiro, como profissional atuante e designado para administrar as Unidades de Saúde deve conhecer, inteirar-se de suas influências sobre o local de trabalho e buscar, com seus pares e em diferentes níveis hierárquicos, alertar sobre as possíveis conseqüências na qualidade do serviço prestado à comunidade.

Para o enfrentamento das dificuldades dos enfermeiros na liderança de sua equipe de trabalho sugere-se utilizar e conciliar as habilidades técnicas, humanas e conceituais, como mais uma maneira profissional de conduzir seu trabalho. As habilidades são assim categorizadas ${ }^{(9)}$ : Habilidade técnica que implica a compreensão e o domínio de um determinado tipo de atividade. Envolve conhecimento especializado, habilidade analítica dentro da especialidade e facilidade no uso de técnicas e do instrumental da disciplina específica. A habilidade técnica é adquirida por meio de experiência, educação e treinamento profissional. Habilidade humana que se refere à capacidade de trabalhar com outras pessoas e obter resultados por meio destas, compreendendo-as e motivando-as, tanto individualmente quanto em grupo. Habilidade conceitual, também conhecida como visão sistêmica, significa habilidade para visualizar a organização como um conjunto integrado. Implica a capacidade de se posicionar no ponto de vista da organização, perceber como as várias funções são interdependentes e como uma alteração em uma delas afeta todas as demais. O administrador tem de saber conviver, compreender e lidar com situações complexas e ambíguas. Isto requer maturidade, experiência e capacidade para analisar pessoas e situações.

\section{CONSIDERAÇÕES FINAIS}

Acreditamos que para ser um enfermeiro qualificado e competitivo no mercado de trabalho além do saber fazer, desenvolvido pelas habilidades técnicocientífica, é necessário investir nas habilidades humanas, saber gerir pessoas, aprender a gerenciar conflitos e visualizá-los de maneira positiva, construtiva, olhá-lo como potencial de crescimento do grupo em busca de objetivos comuns, não reprimi-los nem condená-los, e sim deixá-los florescer e controlar a situação para que não haja extrapolamento.

As habilidades conceituais incluem uma visão holística que vai além da sua função, engloba a instituição que desempenha suas atividades, os serviços que prestam assistência a ela e o ambiente externo. Com o desenvolvimento e aprimoramento deste conjunto de habilidades e os atributos que são características inerentes a cada indivíduo, o enfermeiro apresenta maiores condições para gerenciar os serviços de enfermagem com responsabilidade e competência.

No decorrer da história persistindo até os dias de hoje, o papel do enfermeiro ampliou-se gradativamente, o que acaba exigindo maiores habilidades nos seus serviços. Para manter-se atualizados com as mudanças, os enfermeiros assumiram responsabilidades cada vez mais complexas, adquirindo mais conhecimento, e compreensão da própria enfermagem ${ }^{(10)}$.

Cabe ao enfermeiro que se faça presente no seu trabalho assistencial e administrativo, reconhecendo seus funcionários conforme suas características e habilidades, não esquecendo que possuem valores e crenças que devem ser respeitadas e levadas em consideração ${ }^{(10)}$.

Este estudo mostrou que os enfermeiros entrevistados, mesmo a maioria não realizando cursos na área de gerenciamento de conflitos, gestão de pessoas, visualizam as situações conflitivas como forma de crescimento do grupo e apontam caminhos nas resoluções dos problemas no ambiente de trabalho.

\section{REFERÊNCIAS}

1. Marx LC. Competências da enfermagem. Rio de Janeiro: EPUB; 2006.

2. Ciampone $\mathrm{MH}$, Peduzzi M. Trabalho em equipe e processo grupal. In: Kurgant P. Gerenciamento dos serviços de enfermagem. Rio de Janeiro: Guanabara Koogan; 2005.

3. Santos GF. Formação do enfermeiro na perspectiva das competências: uma breve reflexão. Rev Bras Enferm. 2004 Jan/Fev;57(1):66-71.

4. Kurcgant P. Gerenciamento dos serviços de enfermagem. Rio de Janeiro: Guanabara Koogan; 2005.

5. Marquis BL, Huston CJ. Administração e liderança em enfermagem. $4^{\mathrm{a}}$ ed. Porto Alegre: Atheneu; 2005. 
6. Ciampone MHT, Kurcgant P. Gerenciamento de conflitos e negociação. In: Kurgant P. Gerenciamento dos serviços de enfermagem. Rio de Janeiro: Guanabara Koogan; 2005.

7. Minayo MCS, Sanches O. Quantitativo-qualitativo: oposição e complementariedade? Cad Saúde Públ. 1993 Jul/Set;3(9):239-48.

8. Cecagno D, Cecagno S, Siqueira HCH. Satisfação de uma equipe de enfermagem quanto a profissão e emprego num hospital do sul do estado do Rio Grande do Sul. Cogitare Enferm. 2003 Jan/Jun;8(1):34-8.

9. Robbins SP. Comportamento organizacional. $9^{\mathrm{a}}$ ed. São Paulo: PrenticeHall; 2002.

10. Gindri L, Medeiros HMF, Zamberlan C, Costenaro RGS. A percepção dos profissionais de enfermagem sobre o trabalho dos enfermeiros. Cogitare Enferm. 2005 Jan/ Abr;10(1):34-41. 